\title{
A Rare Case Report of Neurodegenerative Disease: Duchenne Muscular Dystrophy in Two Male Siblings
}

\author{
${ }^{1} \mathrm{~B}$ Suneja, ${ }^{2} \mathrm{ES}$ Suneja, ${ }^{3} \mathrm{VK}$ Adlakha, ${ }^{4} \mathrm{P}$ Chandna
}

\begin{abstract}
Duchenne muscular dystrophy (DMD) is an recessive $X$-linked mediated, musculoskeletal disorder that affects only males. It is the most common and severe form of muscular dystrophy where there is failure to manufacture dystrophin. Clinically, it is characterized by progressive muscle wasting eventually leading to premature death. This case report describes the genetic, oral and systemic findings in two cases of DMD in male siblings.
\end{abstract}

Keywords: Disorder, Hereditary, Recessive.

How to cite this article: Suneja B, Suneja ES, Adlakha VK, Chandna P. A Rare Case Report of Neurodegenerative Disease: Duchenne Muscular Dystrophy in Two Male Siblings. Int J Clin Pediatr Dent 2015;8(2):163-165.

\section{Source of support: Nil}

Conflict of interest: None

\section{INTRODUCTION}

Duchenne muscular dystrophy (DMD) is an inherited musculoskeletal disorder that affects only males (recessive X-linked mediated). It is the most common and severe form of muscular dystrophy. ${ }^{1}$ It is characterized by progressive muscle wasting that begins at 3 to 5 years, delay in motor development and eventually wheelchair confinement followed by premature death at about 30 years from cardiac or respiratory complications.

The purpose of this paper is to describe two cases of DMD in male siblings.

\section{CASE REPORT}

Two boys aged 7 and 5 years were brought to a private dental clinic in Meerut, Uttar Pradesh, India for dental

\footnotetext{
${ }^{1}$ Professor, ${ }^{2-4}$ Reader

${ }^{1}$ Department of Pedodontics and Preventive Dentistry, BJS Dental College, Ludhiana, Punjab, India

${ }^{2}$ Department of Conservative Dentistry and Anatomy, BJS Dental College, Ludhiana, Punjab, India

${ }^{3,4}$ Department of Pedodontics and Preventive Dentistry Subharti Dental College, Meerut, Uttar Pradesh, India

Corresponding Author: VK Adlakha, Reader, Department of Pedodontics and Preventive Dentistry, Subharti Dental College, Meerut, Uttar Pradesh, India, e-mail: adlakhavivek@ gmail.com
}

treatment. They are a family with three boys (Fig. 1). The two older children aged 7 and 5 years had been diagnosed with DMD at the age of 5 and 3 years respectively. Their parents gave a history of repeated falls, fatigue and inability to climb stairs and muscle weakness for both affected children. Their intelligence quotient (IQ) was in the normal range. The third and youngest child was 3 years old and yet unaffected.

On clinical examination, the oldest child presented with difficulty in standing, walking and stair climbing, obese appearance, proximal weakness, calf hypertrophy, and hamstring muscle contracture (Fig. 2). The other affected child presented with similar difficulty in stair climbing, muscle weakness and calf hypertrophy (Fig. 3). Dental findings in both affected children were open bite and enlarged tongue. Oral prophylaxis was performed for both affected children.

The creatine kinase (CK) levels were elevated to 22040 and $19800 \mathrm{U} / \mathrm{L}$ respectively for the oldest and middle child. Electromyographic results were abnormal favoring myopathy for both children. Multiplex polymerase chain reactions (PCR) of the older child revealed dystrophin gene deletion in exons 45, 48, 51, 50, 52 and 60, as seen on agarose gel analysis. For the middle-ranked child dystrophin gene deletion in exons 45, 47, 49 and 50 was present.

Both affected children were undergoing treatment for DMD which included daily physiotherapy, steroid therapy and regular assessment for progressive muscle and cardiac/respiratory damage.

\section{DISCUSSION}

Duchenne muscular dystrophy is the most common muscle dystrophy in India as well as the world..$^{2}$ It is caused by mutations in the dystrophin gene as a result of which the body is unable to synthesize the protein dystrophin that is required for muscle contraction. Each time the muscle contracts, muscle damage occurs, which is repaired - but with the deficient protein. Thus, the repaired muscle is also a damaged one. This continuous cycle of damage and repair and eventually replacement of muscle with fibrofatty tissue is responsible for the clinical signs of progressive muscle wasting and degeneration that is usually apparent by 3 to 4 years. ${ }^{3,4}$ In 


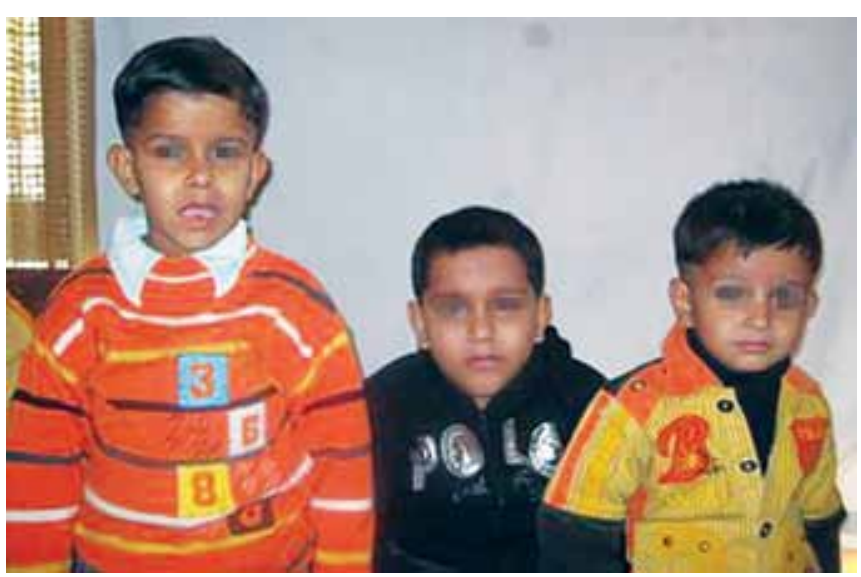

Fig. 1: Three male siblings of a family, of which two older children are affected with DMD

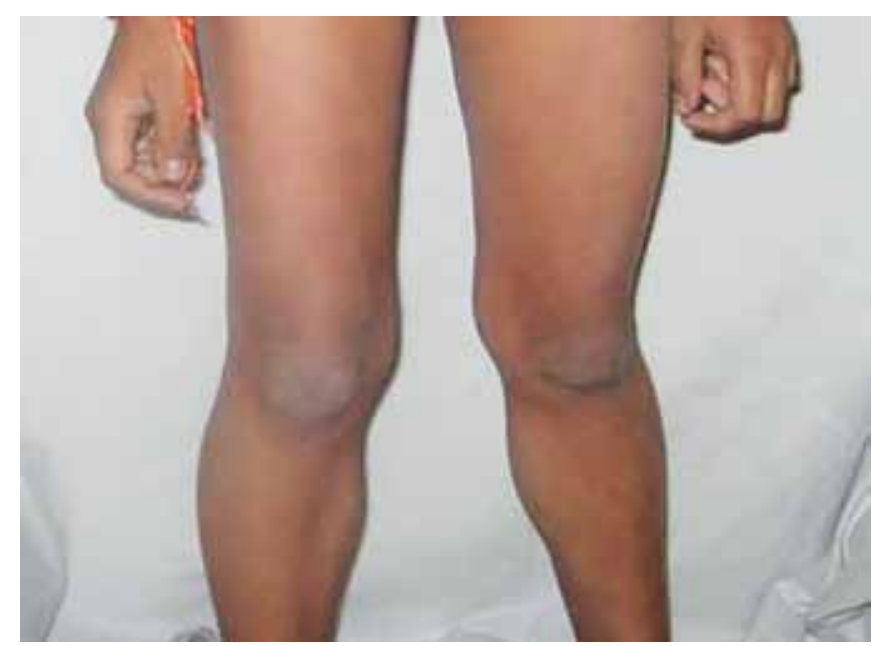

Fig. 3: Calf hypertrophy in the middle-ranked sibling affected with DMD

the present case, the affected older and middle siblings were diagnosed at about 5 and 3 years respectively due to signs of delayed motor development, difficulty in walking and stair climbing, inability to stand from sitting position without support ('Gower's sign'), fatigue, repeated falls and muscle weakness.

Oral signs include: wide dental arches, large tongue, delayed eruption, open bite and retrognathic facial morphology. The development of malocclusions in DMD patients is linked to the involvement of the orofacial muscles by the disease. ${ }^{5,6}$ The children in our case presented with enlarged tongue and open bite.

Diagnosis is confirmed by high serum marker levels of $\mathrm{CK}$, genetic analysis or muscle biopsy. Elevated levels of CK in the serum above normal (35-174 U/L) are characteristic in DMD patients. The increased permeability of the sarcolemma that is damaged due to repeated contractions in DMD patients leads to leakage of proteins, such as CK into the plasma. ${ }^{4,7}$ In both affected children in our case, the CK levels were markedly above normal (22040 and $19800 \mathrm{U} / \mathrm{L}$ for older and middle siblings respectively).

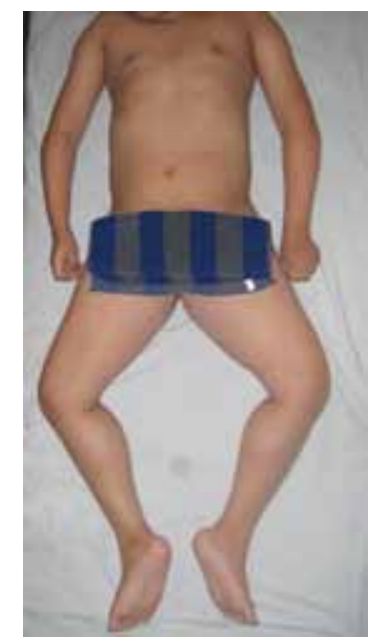

Fig. 2: Knee and hamstring contracture in the oldest sibling affected with DMD

The underlying cause of DMD is a mutation (most commonly deletions) in the dystrophin gene on the Xp21 chromosome. ${ }^{8}$ The dystrophin gene consists of 79 exons and this is the largest gene in the human genome. Currently, PCR amplification of 19 deletion prone exons (exons 1, 3, 4, 6, 8, 12, 13, 17, 19, 43, 44, 45, 47, 48, 49, 50, 51, 52 and 60) is commonly used to screen deletion mutations. ${ }^{9}$ In our case, deletions of dystrophin gene was seen on exons $45,48,51,50,52$ and 60 . Correlation between exonic deletion and certain clinical features like ambulation, mental retardation, and histological findings has been noted. ${ }^{10}$ The children in our case did not suffer from mental retardation.

Current management of DMD involves physiotherapy and corticosteroid therapy which delays but does not cure the disease. Prenatal counseling and various other genetic modalities are being tested to offer hope in this progressive and eventually fatal muscle dystrophy to prolong and improve the quality of life in such patients.

\section{REFERENCES}

1. Baiardini I, Minetti C, Bonifacino S, Porcu A, Klersy C, Petralia P, Balestracci S, Tarchino F, Parodi S, Canonica GW, et al. Quality of life in Duchenne muscular dystrophy: the subjective impact on children and parents. J Child Neurol 2011 Jun;26(6):707-713.

2. Nadkarni JJ, Dastur RS, Viswanathan V, Gaitonde PS, Khadilkar SV. Duchenne and Becker muscular dystrophies: an Indian update on genetics and rehabilitation. Neurol India 2008 Jul-Sep;56(3):248-253.

3. Davidson ZE, Truby H. A review of nutrition in Duchenne muscular dystrophy. J Hum Nutr Diet 2009 Oct;22(5):383-393.

4. Kaspar RW, Allen HD, Montanaro F. Current understanding and management of dilated cardiomyopathy in Duchenne and Becker muscular dystrophy. J Am Acad Nurse Pract 2009 May;21(5):241-249.

5. Matsuyuki T, Kitahara T, Nakashima A. Developmental changes in craniofacial morphology in subjects with 
Duchenne muscular dystrophy. Eur J Orthod 2006 Feb; 28(1):42-50.

6. Kiliaridis S, Katsaros C. The effects of myotonic dystrophy and Duchenne muscular dystrophy on the orofacial muscles and dentofacial morphology. Acta Odontol Scand 1998 Dec; 56(6):369-374.

7. Palmieri B, Tremblay JP, Daniele L. Past, present and future of myoblast transplantation in the treatment of Duchenne muscular dystrophy. Pediatr Transplant 2010 Nov;14(7): 813-819.
8. Strober JB. Genetics of pediatric neuromuscular disease. Curr Opin Pediatr 2000 Dec;12(6):549-553.

9. Matsuo M. Duchenne and Becker muscular dystrophy: from gene diagnosis to molecular therapy. IUBMB Life 2002 Mar; 53(3):147-152.

10. Swaminathan B, Shubha GN, Shubha D, Murthy AR, Kiran Kumar HB, Shylashree S, et al. Duchenne muscular dystrophy: a clinical, histopathological and genetic study at a neurology tertiary care center in Southern India. Neurol India 2009 Nov-Dec;57(6):734-738. 


\section{Erratum}

The sequence of authors in the article "Evaluation of the Load-bearing Capacity of Fractured Incisal Edge of Maxillary Permanent Central Incisors restored with a Glass Fiber-reinforced Nanocomposite: An in vitro Study" [Jan-April 2015, Vol. 8(1):22-29] KT Srilatha, B Nandlal, Kanika Singh Dhull, PS Praveen Kumar was an error and should be read as PS Praveen Kumar, KT Srilatha, B Nandlal, Kanika Singh Dhull. 